\title{
СОПОСТАВИТЕЛЬНЫЙ АНАЛИЗ ФРАЗЕОЛОГИЧЕСКИХ ЕДИНИЦ С АНТОНИМИЧНЫМИ КОМПОНЕНТАМИ В АНГЛИЙСКОМ И КАЗАХСКОМ ЯЗЫКАХ
}

\section{Тукешова Н.М.}

Актуальность. Фразеологические единиць с антонимичными компонентами двух исследуемых языков ранее не были исследованы. Поскольку английский и казахский языки являются неродственныли и разноструктурными языками, определение их схожести и различия, а также специфических характеристик требует тщательного изучения.

Цель. Сопоставление фразеологических единиц с антонимичными компонентами двух неродственных языков с точки зрения их лексико-грамматических особенностей и выявление их сходств и различий. Для достижения этой цุели нами были поставлены следующие задачи: выявить изученность фразеологических единии с антонимичными компонентами в сопоставительном аспекте в английском и казахском языках; определить различия и сходства фразеологических единиц с антонимичными компонентами двух разноструктурных языков, выявить специфические черты каждого языка.

Методы исследования. Работа опирается на следующие методы: метод фразеологического описания, лексико-грамматический анализ, компонентный анализ. Методом сплошной выборки из лексикографических источников английского, казахского и русского языков были найдены фразеологические единицы с антонимичными компонентами.

Результаты. Фразеологические единицы с антонимичными компонентами отражаются во всех лексико-грамматических разрядах языка, также анализ выявил, что фразеологические единицы в двух рассматриваемых языках могут различаться по способу образова- 
ния связей между компонентами. Антонимичные компоненты в их составе влияют на иелостное значение фразеологических единиц.

Область применения результатов. Материаль исследования могут быть использованы в разработке курсов по лексикологии и фразеологии.

Ключевые слова: фразеологическая единица; антоним; сопоставительный анализ; английский язык; казахский язык.

\section{COMPARATIVE STUDY OF THE PHRASEOLOGICAL UNITS WITH ANTONYMOUS COMPONENTS IN THE ENGLISH AND KAZAKH LANGUAGES}

\section{Tukeshova N.M.}

Relevance. Phraseological units with antonymous components of the two studied languages have not been previously studied. Since the English and Kazakh languages are unrelated and different-structured languages, determining their similarities and differences, as well as specific characteristics, requires careful study.

Purpose. Comparison of phraseological units with antonymous components of two unrelated languages from the point of view of their lexical and grammatical features and identification of their similarities and differences. To achieve this goal, we set the following tasks: to reveal the study of the comparative aspect of phraseological units with antonymous components in the English and Kazakh languages; to determine the differences and similarities of phraseological units with the antonymous components of two different-structured languages, to identify the specific features of each language.

Methods. The work is based on the following methods: method of phraseological description, lexical and grammatical analysis, component analysis. The method of continuous sampling from lexicographic sources of the English, Kazakh and Russian languages was used to find phraseological units with antonymous components. 
Results. Phraseological units with antonymous components are reflected in all lexical and grammatical categories of the language, and the analysis also revealed that phraseological units in the two languages under consideration can differ in the way of forming connections between components. Antonymous components in the phraseological units affect their integral meaning.

Practical implications. Research materials can be used in the development of courses in lexicology and phraseology.

Keywords: phraseological unit; antonym; comparative analysis; English; Kazakh.

\section{Введение}

Как и во многих языках, в английском и казахском языках имеются фразеологические единицы. Фразеологические единицы столь же разнообразны по составу, как и по соотношению компонентов. В данном случае предметом нашего исследования являются фразеологические единицы с антонимичными компонентами. Хотя их объем не настолько велика. В настоящее время были исследованы отдельно и фразеологические единицы, и антонимы в рассматриваемых языках, однако фразеологические единицы с антонимичными компонентами в сопоставительном аспекте не изучались, поэтому это определяет новизну данной статьи.

В настоящее время сопоставительное изучение фразеологических единиц неродственных языков приобретает все больший интерес многих ученых. Как отмечат Е.Ф. Арсентьева сопоставительное исследование можно проводить с фразеологическими единицами, которые имеют однотипные структуры, функции и компоненты [2, c. 3]. На сегодняшний день есть немало работ по фразеологическим единицам в сопоставительном аспекте таких исследователей как, Г.М. Полькина, Е.Ф. Арсентьева, Ф.Х. Тарасова, Л.Т. Мифтахутдинова. Они изучали фразеологические единицы с разных аспектов. Например, в работе Е.Ф. Арсентьевой рассматривались структурно-грамматические, семантические особенности фразеологических единиц, а также фразеологические эквиваленты, аналоги и их безэк- 
вивалентность [2]. Ф.Х. Тарасова проводит анализ английских и татарских фразеологических единиц с компонентом пища, определяя их этимологическую, семантико-грамматическую классификацию [18]. В своей диссертационной работе Л.Т. Мифтахутдинова проводит сопоставительный анализ в плане выражения и содержания фразеологических единиц с компонентом прилагательным, а также выясняет их системные связи в английском и турецком языках и т.д. Она также отмечает, что исследование фразеологических единиц с общим компонентом способствует решению обсуждаемого вопроса во фразеологии о функции компонентов в образовании значений, а также выяснить языковые универсалии, присущие всем языкам [12, с. 3].

Фразеологические единицы, как замечает Г.Б. Антрушина, являются самыми красочными, живописными и выразительными частями словарного запаса любого языка [1, с. 225]. Хотя на сегодняшний день есть немало исследовательских работ по фразеологическим единицам, еще нет их точной классификации и устоявшего мнения о них. И. Кенесбаев отметил, что фразеологических единиц можно рассматривать только с точки зрения синтаксических, семантических характеристик, частей речи, семантической классификации слов и подобных характеристик [6, с. 617]. В зависимости от сложности структурных, семантических аспектов, а также из-за наличия какого-либо компонента в составе фразеологических единиц направления методов исследования могут различаться. Фразеологические единицы с антонимичными компонентами недостаточно подвергались изучению именно в сопоставлении английского и казахского языка. Однако имеется работа Г.М. Полькиной, которая совпадает с направлением нашего исследования. В её работе изучались английские фразеологические единицы с антонимичными компонентами в сопоставлении с татарским языком. В казахском языке же подобное исследование вовсе не проводилось. Компоненты-антонимы с составе фразеологических единиц в понимании Г.М. Полькиной, являются отдельными элементами фразеологизма, которые обладают характерным употреблением [13, с. 55]. То есть, наше восприятие значения фразеологических единиц может 
зависеть от их компонентов. Учитывая формальные характеристики антонимичности, можно отметить, что компоненты-антонимы играют роль сигнальных устройств внутреннего сопротивления в значении фразеологических единиц, как принято, они выступают в роли смыслового центра, то есть компонента фразеологических единиц, который определяет целостное значения фразеологических единиц [16, с. 45].

Для проведения анализа методом сплошной выборки из лексикографических источников английского, казахского и русского языков были найдены фразеологические единицы с антонимичными компонентами. В основу нашего анализа была положена классификация фразеологических единиц А.В. Кунина [9].

Согласно классификации А.В. Кунина, среди исследуемых фразеологических единиц с антонимичными компонентами мы отмечаем субстантивные, адъективные, адвербиальные, глагольные, междометные и модальные фразеологические единицы.

И. Кенесбаев отмечает, что классификация фразеологических единиц по частям речи является одной из основных задач, однако невозможно заявить, что в этих фразеологических единицах есть твердо сформированные части речи [6, с. 617].

Субстантивные фразеологические единицы обозначают предмет или субстантированное действие. Они функционально соотносимы с существительным, то есть их стержневым компонентом являются существительные и обозначают предметность или понятие [5, с. 169]. Субстантивные фразеологические единицы с антонимичными компонентами встречаются в наибольшем количестве в английском языке, а в казахском их количество мало среди обнаруженных нами фразеологических единицах с антонимичнами компонентами: beauty and the beast - красавица и чудовище [8, с. 72]; the beginning of the end - начало конца [Там же, с. 75]; power of life and deathвласть над жизнью и смертью; обладать силой жизни и смерти [Там же, с. 600]; көзінің аzы мен құарасы - единственное утешение, одна радость в глазу [6, с. 263]; ақ сақал, құара сақал-старые и молодые [Там же, с. 25]. 
В исследуемых языках найдены фразеологические единицы с антонимичными компонентами с сочинительной (соединительно-сочинительная, разделительно-сочинительная, соединительно-противительная) и подчинительной связью.

В английском языке можно встретить фразеологические единицы с антонимичными компонентами с подчинительной связью, образованные при помощи предлогов:

A sheep among wolves - овечка среди волков [8, с. 675].

The beginning of the end - начало конца [Там же, с. 75].

В этих примерах лексемы sheep, beginning и лексемы wolves, end соединяются с помощью предлогов among и of.

A big frog in a little pond - большая лягушка в маленьком пруду [Там же, с. 300].

В этом примере сочетание лексем big frog и сочетание лексем little pond соединены при помощи предлога in. В исследуемых фразеологических единицах самыми распространенными предлогами считаются in и of.

В казахском языке подчинительная связь образуется при помощи добавления окончаний падежей, так как в казахском языке нет предлогов: Ораздыныьц ұлыl, Жиырлының қызыь - сын счастливого, дочь несчастного [17, с. 137].

Среди рассматриваемых фразеологических единиц обоих языков можно найти двухкомпонентные и трехкомпонентные, многокомпонентные фразеологические единицы: bouquets and brickbats захваливание и поношение [8, с. 102]; cross questions and crooked answers - игра в вопросы и ответы [9, с. 614]; көзінің авы мен құара$c b l$ - единственное утешение, одна радость в глазу [6, с. 263]; өмір я өлім мәселесі - дело жизни и смерти [3, с. 36].

В английском языке двухкомпонентных субстантивных фразеологических единиц можно выделить с точки зрения числа, в котором стоят компоненты фразеологических единиц, например,

Likes and dislikes - симпатии и антипатии [8, с. 458].

В этом примере оба компонента стоят во множественном числе. Pro and con - за и против [Там же, с. 605]. 
В этом же примере оба компонента стоят в единственном числе. Хотя была найдена фразеологическая единица, где оба компонента стоят во множественном числе the pros and cons.

В казахском языке была обнаружена одна двухкомпонентная фразеологическая единица, компоненты которой стоят в единиственном числе:

Ақ̧пен қ̧ара - белое и черное; правильное и неправильное [6, с. 25].

Сочинительная связь субстантивных фразеологических единиц с антонимичными компонентами в английском языке могут образоваться при помощи союзов or, and, а в казахском языке при помощи союзов “пен, я, мен, әрі”: heads or tails - орел или решка [19, c. 24]; ins and outs - подробности чего-либо [8, с. 408]; өмір я өлім мәселесі-дело жизни и смерти [3, с. 36]; ақ пен қ̧ара-правильное и неправильное [6, с. 25].

Также среди исследуемых фразеологических единиц встречаются сложные фразеологические единицы, где две лексемы с подчинительной связью соединены сочинительной связью с помощью союза and: Bone of one's bone and flesh of one's flesh - кость от кости и плоть от плоти [8, с. 96].

Что касается антонимичных компонентов в составе субстантивных фразеологических единиц, то можно сказать, что наблюдается наличие узуальных антонимов: long hair and short wit - волос долог, да ум короток [8, с. 343], еңкейген кәрі, еңбектеген жас-старые и молодые [7, с. 66]; окказиональных антонимов: bouquets and brickbats - хвала и поношение [8, с. 102], әрі күлкі, әрі түрпі - и смех, и грех [3, с. 82].

К тому же в рассматриваемых фразеологических единицах английского и казахского языков встречаются случаи с двойным противопоставлением в составе одной фразеологической единицы. К примеру, cross questions and crooked answers - игра в вопросы и ответы [9, с. 614], в данном случае внутри фразеологической единицы противопоставляются прилагательные cross - crooked (поперечный - кривой), существительные questions - answers (вопросы -

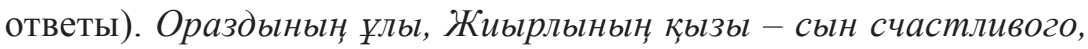


дочь несчастного [17, с. 137], здесь противопоставляются прилагательные Ораздының - Жиырлының (счастливый - несчастный), существительные қызыз - ұлы (дочь - сын). Можно сказать, что если убрать хоть один из этих компонентов, то их значение теряют свою усиленную выразительность. Эти фразеологические единицы в своем целостном значении относятся к существительным, поэтому мы отнесли их к субстантивным фразеологическим единицам. Таким образом, можно отметить, что фразеологические единицы с антонимичными компонентами могут быть аналогичны существительным, прилагательным, наречиям, глаголам по своему лексико-грамматическому значению, несмотря на то, что антонимичные компоненты в их составе могут выступать в совсем других.

Адъективные фразеологические единицы функционально соотносимы с прилагательными, имеют значение качественной характеристики и выступают в функции определения. Стержневым компонентом является прилагательное [2, с. 30]. Адъективные фразеологические единицы бывают компаративными и некомпаративными. Компаративные фразеологические единицы возникают, когда существует необходимость в дополнительной информации, кроме информации, получаемой через первые компоненты сравнения [9, c. 139]. К компаративным фразеологическим единицам можно отнести: as clear as mud - совершенно непонятный, неясно [10, с. 64]; more dead than alive - смертельно усталый [8, с. 203]. В примере as clear as mud первый компонент употребляется в буквальном смысле, а второй компонент определяет характер оценки, также ей присуща преувеличение для экспрессивности. Сравнение идет при помощи союза as ... as, однако можно встретить фрвзеологические единицы без начального союза as: clear as mud. То есть их можно считать квантитативными вариантами. А в примере more dead than alive можно увидеть, что в английском языке также имеются компаративные фразеологические единицы с прилагательными в сравнительной степени.

В казахском языке: ай мен күндей - красивый; как солнце и луна [6, с. 21]; есік пен төрдей - длинный, большой [7, с. 70]. В этих 
примерах фразеологических единиц казахского языка сравнение осуществляется при помощи суффиксов “-дай, -дей”.

К некомпаративным фразеологическим единицам относятся: open and shut - простейший, несложный [8, с. 554]; black or white черное или белое [Там же, с. 87]; Ұзында өшті, қысққада кекті враждующие [17, с. 541]; іші өлген, сырт сау - разочарованный в жизни [6, с. 587].

Адъективные фразеологические единицы с антонимичными компонентами в основном относятся к человеку, а также могут иметь как положительный характер оценки, так и отрицательный: nothing but skin and bones - очень худой [20, с. 458]; more dead than alive - смертельно усталый $[8,203]$; ай мен күндей әмбеге бірдей - прекрасный [6, с. 21]; пайдасынан зияны көn-себе дороже стоит; причиняющий больше вреда, чем пользы [3, с. 180]. В адъективных фразеологических единицах также наблюдается наличие фразеологических единиц с двойным противопоставлением в составе одной фразеологической единицы. К примеру в английском языке: penny wise and pound foolish-рискующий большим ради малого [8, с. 572]. В этом примере имеются две антонимичной пары, противопоставляются существительные penny - pound (пенни, монета в 1 цент - фунт) и прилагательные wise - foolish (мудрый - глупый). В казахском языке : ағама жеңзем сай, апама жездем сай - два сапога пара [6, с. 10]. В этом примере точно также имеется две антонимичной пары, в котором противопоставляются существительные: aza - ana (старший братстаршая сестра) и жеңце - жезде (сноха - зять). Однако целостное значение этих фразеологических единиц соотносится с прилагательным, поэтому мы отнесли их к адъективным фразеологическим единицам. Целостное значение этих фразеологических единиц возможно предположить по смыслу компонентов в их составе.

Адвербиальные фразеологические единицы функционально соотносимы с наречием, их стержневым компонентом является наречие. Адвербиальные фразеологические единицы включаются в общее значение или качественную характеристику действия, состояния или признака [21, с. 52]. Адвербиальные фразеологические 
единицы бывают качественные и обстоятельственные. Качественные адвербиальные фразеологичесские единицы характеризуют их с качественной стороны, то есть по признакам образа действия, степени, меры. К ним можно отнести: by hook or by crook - всеми правдами и неправдами [9, с. 145], әне-міне дегенше - незаметно, быстро [3, с. 188]. Обстоятельственные адвербиальные фразеологические единицы обозначают условия, в которых совершается действия [9, c. 146]. К ним относятся: From John o'Groat's to Land's End- с одного конца страны до другого [8, с. 417], көзді ашып-жұмzаниа моментально, в мгновение ока [3, с. 85], басынан бастап, құара бақұайына шейін - с головы до ног [Там же, с. 179]. Адвербиальные фразеологические единицы с антонимичными компонентами в английском и казахском языках бывают как с подчинительной связью, так и с сочинительной связью. К адвербиальным фразеологическим единицам с подчинительной связью можно отнести следующие фразеологические единицы: from soup to nuts - от начала до конца [20, с. 270]; as night follows day - неизбежно [8, с. 534]; көздi aшыл-жұмzанша - в мгновение ока [3, с. 85]; басынан аявына дейiн - от начала до конца [Там же, с. 118]. С сочинительной связью: more or less - более или менее [8, с. 465]; here and there - там и сям [Там же, с. 384]; sooner or later - рано или поздно [Там же, с. 703]; өлі мен тірінің арасында - между жизнью и смертью [6, с. 432]; өң мен түстей - не верить глазам [Там же, с. 435].

Что касается антонимичных компонентов в составе адвербиальных фразеологических, они в основном употребляются для сравнения одного объекта, качества, признака с другим. Адвербиальные фразеологические единицы с двойным противопоставлением имеются в казахском языке, однако не встретились в английском: aстыңдъы ерні жер mipen, Үстіңзгі ерні көк тіреп - злой (один из видов преувеличения в народной литературе казахского языка) [6, с. 54]. В этом примере астығы - үстіңгі (верхний - нижний) являются служебными именами, а жер - көк (земля - небо) существительными. Как и в других группах, мы отнесли фразеологическую единицу к адвербиальным по ее значению в целом. 
Глагольные фразеологические единицы с антонимичными компонентами занимают наибольшее количество исследуемых фразеологических единиц, как в английском, так и в казахском языке: bind $s m b$. hand and foot - связать кого-то по рукам и ногам [8, с. 346]; be a drop in the ocean - быть каплем в море, маленькое количество [19, c. 70]; blow hot and cold - быть непостоянным, все время менять точку зрения [8, с. 93]; anы кіріп, күni шықты - толкотня, беготня [6, с. 43]; жерден aльı, жерге салды - проклинать, оскорблять [Там же, с. 199]; кең дүние тар болды - разочароваться в мире [Там же, с. 247].

В обоих языках встречаются компаративные и некомпаративные глагольные фразеологические единицы. Компаративные фразеологические единицы в английском языке образуются посредством предлога like, а в казахском посредством суффиксов, таких как дай, дей: to fight like cat and dog - драться как кошка с собакой [8, c. 271]; түймедейді түйедей ету - много шума из ничего [3, с. 78].

В английском языке некомпаративные фразеологические единицы образуются посредством предлогов: wait on smb. hand and footделать всё возможное для кого-то [10, с. 356]; to judge in black and white - делить все на черное и белое [Там же, с. 56].

В казахском же могут употребляться окончания падежей: $a л d b l$ артына қ̧аратпай қ̧ашыру - убежать необдуманно, неосмотрительно [4, с. 43]; өмірдің ащзы-тұщы сысы тату - испытать немало горя $[3$, с. 74$]$.

Специфической чертой английского языка является то, что в нем может использоваться артикль, в то время как артикль в казахском языке отсутствует: throw out a minnow to catch a whale - рискнут пустяком ради большого [8, с. 508]; not able to see the forest for the trees - упускать главное из-за мелочей [22, с. 454].

Касательно антонимичного компонента можно сказать, что в глагольных фразеологических единицах значение глагола может изменяться в зависимости от компонента, то есть образование антонимичных отношений зависит от этого компонента. В ангийском языке антонимичные компоненты в основном стоят в постпозитив- 
ном положении, а в казахском языке в препозитивном. В английском и казахском языках в глагольных фразеологических единицах в антонимичные отношения вступают наречия, прилагательные, существительные, а также сами глаголы: come high, come low - будь что будет, что бы ни было. [8, с. 165], blow hot and cold - быть непостоянным, все время менять точку зрения [Там же, с. 93], play cat and mouse with smb. - играть с кем-либо как кошка с мышью [Там же, с. 134], make or break - возвеличить или погубить кого-либо [Там же, с. 477], кең дүние тар болды - разочароваться в мире [6, с. 247], жерден aльл, жерге салды - проклинать, оскорблять [Там же, с. 199], ішінен кіріп, сыртына шықты - льстить [Там же, с. 586].

В исследуемых глагольных фразеологических единицах также встречаются фразеологические единицы с двойным противопоставлением: heads I win, tails you lose - говорится о ситуации, в которой вы выиграете, что бы ни случилось [8, с. 368], где антонимичные компоненты являются существительными head-tail (голова-хвост), глаголами win - lose (выиграть - проиграть). Аyырдың Ycmi, жеңілдің астымен жүр - избегать трудную сторону дела [6, с. 72]. В этом примере противопоставляются субстантивированные прилагательные aуыр - жеңіл (тяжелый - легкий), служебные имена Ycmi - acmbl (верх - низ). Однако, как и в других группах, мы отнесли их к глагольным фразологическим единицам по их значению в целом.

Междометные и модальные фразеологические единицы с антонимичными компонентами. Междометные фразеологические единицы передают специфику языка, степень экспрессивности, уровень эмоциональности говорящего на том или ином языке [14, с. 78]. Междометная фразеологическая единица встретилась только одна в английском языке, а в казахском вовсе отсутствовало: $d o g$ my cats - ей-богу (выражает удивление) [8, с. 133]. В этом примере dog my cats может употребляться как отдельное предложение или обособленный член предложения, так как междометные фразеологические единицы не могут сочетаться с другими словами. Здесь антонимичными комонентами являются $d o g$ - cat (собака - кошка), они являются окказиональными антонимами, то есть вне фразео- 
логической единицы антонимами не являются. Они в сознании говорящего способствуют формированию ассоциации по контрасту, поэтому в синтагматическом сближении противоположность значений проявляется полностью [13, с. 70].

Модальные фразеологические единицы характеризуют отношение говорящего к теме высказывания [11, с. 32]. Модальные фразеологические единицы с антонимичными компонентами в рассматриваемых фразеологических единицах с антонимичными компонентами двух языков не встретились, однако в казахском языке были найдены фразеологические единицы субъективно модальные по значению. К ним Г. Смагулова в своей работе относит фразеологические единицы, включающие в свой состав вопросительные частицы $[15$, с. 31$]$ : аз ба, көп ne? - более или менее, сколько-нибудь [4, с. 28]; не анда жоқ, не мұнда жоқ- ни туда, ни сюда [3, с. 33]; күлейін бе, жылайын ба? - смеяться или плакать, и смех и горе [Там же, с. 82]. В этих примерах встречаются вопросительные частицы.

\section{Заключение}

Таким образом, исходя из вышеуказанного можно сделать вывод: 1) фразеологические единицы с антонимичными компонентами очень разнообразны, поэтому безусловно заключают в себе все грамматические структуры языка, такие как субстантивные, адъективные, адвербиальные, глагольные, междометные и модальные; 2) существуют сходства и различия фразеологических единиц с антонимичными компонентами, а именно в способах образования связей между компонентами фразеологических единиц посредством предлогов, союзов в английском языке; посредством падежных окончаний в казахском языке; а также наличие и отсутствие артиклей. Что касается, антонимичных компонентов в составе рассматриваемых фразеологических единиц, то можно сказать, что фразеологические единицы с антонимичными компонентами выражают противоложность в составе одной фразеологической единицы. Они в основном употребляются для сравнения одного объекта, качества, признака с другим. В исследуемых фразеологических единицах ан- 
тонимичные компоненты влияют на их целостное значение. Однако для определения лексико-грамматического значения фразеологических единиц следует смотреть на общий смысл самих фразеологических единиц, а не его компонентный состав в отдельности.

Словарный состав английского и казахского языков имеет достаточное количество фразеологических единиц, которые употребляются в любом контексте, в любых обстоятельствах. Хотя фразеологических единиц с антонимичными компонентами в английском и казахском языках меньше, это можно объяснить недостатком или отсутствием исследований. К примеру в казахском языке мало лексикографических источников, посвященных фразеологическим единицам.

Фразеологические единицы с антонимичными компонентами являются универсальным явлением, и рассматривать эти фразеологические единицы как детерминированные только в одном языке нецелесообразно, поскольку они встречаются в составе фразелогических единиц обоих исследуемых языков.

В продолжение изучения фразеологических единиц с антонимичными компонентами в английском и казахском языках планируется расширение фактического материала, подробное изучение с разных аспектов.

\section{Список литературы}

1. Антрушина Г.Б., Афанасьева О.В., Морозова Н.Н. Лексикология английского языка. М.: Дрофа, 2001. 288 с.

2. Арсентьева Е.Ф. Сопоставительный анализ фразеологических единиц. Казань: Изд-во Казанского университета, 1989. 125 с.

3. Балакаев М.Б., Кенесбаев С.К., Копыленко М.М. Русско-казахский фразеологический словарь. Алма-Ата: Наука, 1985. 224 с.

4. Бектаев К. Большой казахско-русский словарь. Алматы: Казахстанский проект разв. гос. языка, 1995. 697 с.

5. Зайнидинов Х.Р. Структурные особенности субстантивных фразеологических единиц в английском и таджикском языках // Ученые записки Худжанского государственного университета им. 
акад. Гафурова Б. Серия гуманитарно-общественных наук, 2016. С. $168-173$.

6. Кенесбаев И. Қазақ тілінің фразеологиялық сөздігі. Алматы: Изд-во Гылым, 1977. 712 с.

7. Кожахметова Х.К., Жайсакова Р.Е., Кожахметова Ш.О. Казахско-русский фразеологический словарь. Алма-Ата: Мектеп, 1988. $224 \mathrm{c}$.

8. Кунин А.В. Англо-русский фразеологический словарь. М.: Русс. яз., 1984. 944 c.

9. Кунин А.В. Курс фразеологии современного английского языка. М.: Высш. шк., Дубна: Изд. центр Феникс, 1996. 381 с.

10. Литвинов П.П. 3500 английских фразеологизмов и устойчивых словосочетаний. М.: Астрель, 2007. 285 с.

11. Лупанова Е.В. фразеологические единицы военной тематики в английском языке // Международный научно-исследовательский журнал, 2017. С. 30-34.

12. Мифтахутдинова Л.Т. Сопоставительный анализ фразеологических единиц с компонентом-прилагательным в английском и турецком языках: автореф. дисс. ... канд. филол. наук. Казань, 2003. 23 с.

13. Полькина Г.М. Сопоставительный анализ фразеологических единиц с антонимичными компонентами в английском и татарском языках: автореф. дисс. ... канд. филол. наук. Казань, 2002. 241 с.

14. Поцелуева Н.В., Федуленкова Т.Н. Сопоставительный анализ вербализации эмоций посредством междометных фразеологических единиц (на материале русской, английской и казахской анималистической фразеологии) // Язык и культура. 2012. С. 72-79.

15. Смагулова Г. Фразеологизмдердің варианттылығы. Алматы: Санат, 1996. $128 \mathrm{c}$.

16. Соловьева Н.В., Шабанова В.П. Антонимия фразеологизмов: формальное и семантическое сходство как критерий противопоставленности единиц // Вестник МГОУ. Серия: Лингвистика. 2015. С. 41-46.

17. Сыздыкова Р. Сөздер сөйлейді. Алматы: Ел-шежіре, 2014. 412 с.

18. Тарасова Ф.Х. Сопоставительный анализ фразеологических единиц английского и татарского языков с компонентами, относящимися к 
фразеосемантическому полю “пища”: автореф. дисс. ... канд. филол. наук. Казань, 1999. 193 с.

19. McCarthy M., O’Dell F. English Idioms in Use. Intermediate. Cambridge University Press, 2017. 178 p.

20. Oxford dictionary of idioms, / edit. by Siefring J. Oxford: Oxford University Press, 2004. 340 p.

21. Sakaeva L.R., Nurullina A.G. Comparative Analysis of Verbal, Adjectival, Adverbial and Modal Phraseological Units with a Lexeme "Devil" in English and Russian Languages // Middle-East Journal of Scientific Research, 2013, pp. 50-57.

22. Spears R.A. McGraw-Hill's dictionary of American idioms and phrasal verbs. The McGraw-Hill Companies, Inc, 2005. 1080 p.

\section{References}

1. Antrushina G.B., Afanas'eva O.V., Morozova N.N. Leksikologiya anglijskogo yazyka [English lexicology]. Moscow.: Drofa, 2001. 288 p.

2. Arsent'eva E.F. Sopostavitel'nyj analiz frazeologicheskih edinic [The comparative analysis of phraseological units]. Kazan': Izd-vo Kazanskogo universiteta, 1989. $125 \mathrm{p}$.

3. Balakaev M.B., Kenesbaev S.K., Kopylenko M.M. Russko-kazahskij frazeologicheskij slovar' [Russian-Kazakh phraseological dictionary]. Alma-Ata: Nauka, 1985. 224 p.

4. Bektaev K. Kazahsko-russkij slovar' [Kazakh-Russian dictionary]. Almaty: Kazahstanskij proekt razv. gos. yazyka, 1995. 697 p.

5. Zajnidinov H.R. Strukturnye osobennosti substantivnyh frazeologicheskih edinic $\mathrm{v}$ anglijskom $\mathrm{i}$ tadzhikskom yazykah [Structural and grammatical peculiarities of substantive phraseological units in English and Tajik languages]. Uchenye zapiski Hudzhanskogo gosudarstvennogo universiteta im. akad. Gafurova B. Seriya gumanitarno-obshchestvennyh nauk, 2016, pp. 168-173.

6. Kenesbaev I. Kazak tilinin frazeologiyalyk sozdigi [Phraseological dictionary of the Kazakh language]. Almaty: Izd-vo Gylym, 1977. 712 p.

7. Kozhahmetova H.K., Zhajsakova R.E., Kozhahmetova SH. O. Kazahsko-russkij frazeologicheskij slovar' [Kazakh-Russian phraseological dictionary]. Alma-Ata: Mektep, 1988. 224 p. 
8. Kunin A.V. Anglo-russkij frazeologicheskij slovar' [English-Russian phraseological dictionary]. Moscow.: Russ. yaz., 1984. 944 p.

9. Kunin A.V. Kurs frazeologii sovremennogo anglijskogo yazyka [Course of Phraseology in Modern English]. Moscow: Vyssh. shk., Dubna: Izd. centr Feniks, 1996. 381 p.

10. Litvinov P.P. 3500 anglijskih frazeologizmov i ustojchivyh slovosochetanij [3500 English phraseologisms and collocations]. Moscow: Astrel', 2007. 285 p.

11. Lupanova E.V. Frazeologicheskie edinicy voennoj tematiki v anglijskom yazyke [English military phraseological units]. International research lournal, 2017, pp. 30-34.

12. Miftahutdinova L.T. Sopostavitel'nyj analiz frazeologicheskih edinic s komponentom-prilagatel'nym $v$ anglijskom i tureckom yazykah [Comparative analysis of phraseological units with an adjective component in the English and Turkish languages]: avtoref. diss. ... kand. filol. nauk. Kazan', 2003. 23 p.

13. Pol'kina G.M. Sopostavitel'nyj analiz frazeologicheskih edinic s antonimichnymi komponentami $v$ anglijskom i tatarskom yazykah [Comparative analysis of phraseological units with antonymous components in the English and Tatar languages]: avtoref. diss. ... kand. filol. nauk. Kazan', 2002. $241 \mathrm{p}$.

14. Pocelueva N.V., Fedulenkova T.N. Sopostavitel'nyj analizverbalizacii emocij posredstvom mezhdometnyh frazeologicheskih edinic (na materiale russkoj, anglijskoj i kazahskoj animalisticheskoj frazeologii) [Comparative analysis of verbalization of emotions by means of interjection phraseological units (based on the material of Russian, English and Kazakh animalistic phraseology)]. Yazyk i kul'tura. 2012, pp. 72-79.

15. Smagulova G. Frazeologizmderdin varianttylygy [Variation of phraseologisms]. Almaty: Sanat, 1996. 128 p.

16. Solov'eva N.V., Shabanova V.P. Antonimiya frazeologizmov: formal'noe i semanticheskoe skhodstvo kak kriterij protivopostavlennosti edinic [Antonymy of phraseologisms: formal and semantic similarity as a criterion for the opposition of units]. Vestnik MGOU. Seriya: Lingvistika. 2015, pp. 41-46. 17. Syzdykova R. Sezder sojlejdi [Words speak]. Almaty: El-shezhire, 2014. $412 \mathrm{p}$. 
18. Tarasova F.H. Sopostavitel'nyj analiz frazeologicheskih edinic anglijskogo i tatarskogo yazykov s komponentami, otnosyashchimisya $k$ frazeosemanticheskomu polyu "pishcha" [Comparative analysis of phraseological units of the English and Tatar languages with components relates to the phraseosemantic group "food"]: avtoref. diss. ... kand. filol. nauk. Kazan', 1999. 193 p.

19. McCarthy M., O’Dell F. English Idioms in Use. Intermediate. Cambridge University Press, 2017. 178 p.

20. Oxford dictionary of idioms. Oxford: Oxford University Press, 2004. $340 \mathrm{p}$.

21. Sakaeva L.R., Nurullina A.G. Comparative Analysis of Verbal, Adjectival, Adverbial and Modal Phraseological Units with a Lexeme "Devil" in English and Russian Languages // Middle-East Journal of Scientific Research, 2013, pp. 50-57.

22. Spears R.A. McGraw-Hill's dictionary of American idioms and phrasal verbs. The McGraw-Hill Companies, Inc, 2005. 1080 p.

\section{ДАННЫЕ ОБ АВТОРЕ}

Тукешова Нургул Максетовна, аспирант кафедры романо-германской филологии Института филологии и межкультурной коммуникации

Казанский (Приволжский) федеральный университет ул. Кремлевская 18, г. Казань, 420008, Российская Федераџия tukeshova_nurgul@mail.ru

\section{DATA ABOUT THE AUTHOR}

Tukeshova Nurgul Maxetovna, postgraduate student of the Department of Romance and Germanic Philology, Institute of Philology and Intercultural Communication

Kazan (Volga region) federal university

18 Kremlyovskaya Str., Kazan, 420008, Russian Federation tukeshova_nurgul@mail.ru

SPIN-code: 4369-3397

ORCID: 0000-0002-1654-3056

Scopus Author ID: 57216807247 